\title{
Comparison of Two Harvesting Methods for the Continuous Production of Indigo Plant (Polygonum Tinctorium) Leaves in a Closed-Cultivation System
}

\author{
Masaru Sakamoto ${ }^{1}$, Dong-An Kim ${ }^{1}$, Keiko Imoto $^{1}$, Yusuke Kitai $^{1} \&$ Takahiro Suzuki ${ }^{1}$ \\ ${ }^{1}$ Faculty of Biology-Oriented Science and Technology, Kindai University, Wakayama 649-6493, Japan \\ Correspondence: Masaru Sakamoto, Faculty of Biology-Oriented Science and Technology, Kindai University, \\ Wakayama 649-6493, Japan. Tel: 81-0736-77-0345. E-mail: sakamoto@waka.kindai.ac.jp
}

Received: December 14, 2016 Accepted: January 18, 2017 Online Published: January 28, 2017

doi:10.5539/sar.v6n2p7

URL: http://dx.doi.org/10.5539/sar.v6n2p7

\begin{abstract}
Although the blue dye indigo has been chemically synthesized for over a century, there is an increasing interest in the indigo plant (Polygonum tinctorium) as a source of natural dyes and medicines. To maintain a stable supply of $P$. tinctorium throughout the year, we examined the effect of two harvesting methods on the leaf yield of this plant under a closed-cultivation system. With method $8 \mathrm{c}-\mathrm{M}$, all shoot branches $>8 \mathrm{~cm}$ of the stem bottom were harvested and under method $2 \mathrm{~b}-\mathrm{M}$, all branches, but two, were harvested at the stem bottom. Both methods enabled sustainable leaf yields from the same plants over 1 year. The total weight of shoot branches harvested by $8 \mathrm{c}-\mathrm{M}$ was $1.86-3.11$ times higher that of shoot branches harvested by $2 \mathrm{~b}-\mathrm{M}$. Harvesting by $8 \mathrm{c}-\mathrm{M}$ resulted in shoot branch weights lower than those from plants harvested with the $2 \mathrm{~b}-\mathrm{M}$. Leaf/shoot ratio was increased in plants harvested by $8 \mathrm{c}-\mathrm{M}$. The content of indican, the precursor of indigo, in leaves was not significantly different between the two harvesting methods. Our data may provide a new continuous cultivation method of leaf crops all over years in controlled-cultivation systems.
\end{abstract}

Keywords: Polygonum tinctorium, indican, indigo, year-round cultivation, harvesting methods, closed-cultivation systems

\section{Introduction}

Indigo is a blue dye that was being extracted from the indigo plant (Polygonum tinctorium) until the end of the 19th century, when chemically synthetized indigo almost completely replaced natural indigo (Bechtold et al., 2002). Consequently, the areas covered with P. tinctorium decreased on a wide scale and cultivation techniques experienced stagnation. There is currently a renovated needs of indigo plants because of the demand for natural dyes and daily necessities such as soap and plastic products (Velho et al., 2017). Indigo is also used in traditional Chinese medicines to treat systemic psoriasis and leukemia (Koo \& Arain, 1998; Xiao et al., 2002).

In Japan, $P$. tinctorium is utilized as a traditional natural dye and is mainly cultivated in the Tokushima Prefecture (Ricketts, 2006). The colorless precursor of indigo, indican, is present in P. tinctorium and is chemically converted to the blue dye indigo by hydrolysis and oxidation (Minami et al., 2000). In addition to being the source of the natural dye, P. tinctorium is also of pharmacological significance. An increasing number of new pharmaceutical agents with suppressive effects against cancer, inflammation, allergy and microbial growth are obtained from its leaf extracts (Hashimoto et al., 1999; Kunikata et al., 2000; Koya-Miyata et al., 2001; Micallef et al., 2002; Iwaki \& Kurimoto, 2002). Thus, a year-round steady supply of $P$. tinctorium leaves is required. However, $P$. tinctorium is an annual short-day plant with a limited leaf harvest period in the field. Moreover, flowering decreases indican concentration in the leaves. Therefore, new cultivation methods for the continuous production of $P$. tinctorium without flowering might be required.

To date, the production of indican and related compounds in vitro has been attempted in cell and root-hair cultures of P. tinctorium (Chung et al. 1996; Kim et al. 1996; Young-Am et al., 2000), However, these approaches yield indican concentrations that are much lower than those present in fresh leaves (Minami et al., 2000; Campeol et al., 2006). Because indican is mainly present in leaves and is rarely found in other parts, such as stems, roots, and flowers (Minami et al., 2000), to maximize the yield of indican from plants, efficient production strategies of leaves are required. Recently, plant factories have been developed for the sustainable 
production of many leafy vegetables throughout the year. To our knowledge, there is no experimental attempt to grow $P$. tinctorium in a closed-cultivation system. Therefore, we designed and tested two harvesting methods for the continuous leaf production of this annual plants in a closed-cultivation system.

\section{Method}

\subsection{Plant Material and Growth Condition in a Closed-Cultivation System}

Indigo plant seeds (Polygonum tinctorium cv. 'Kosenbon' and 'Kojoko') were pregerminated for 3 days at $20^{\circ} \mathrm{C}$ in the dark. Germinated seeds were sown in sponge cubes of $2 \times 2 \times 2-\mathrm{cm}$ in size and grown under $200 \mu \mathrm{mol} \mathrm{m}^{-2}$ $\mathrm{s}^{-1}$ photosynthetic photon flux (PPF) for $16 \mathrm{~h}$ using fluorescent lamps (FL40SBR-A; NEC Co., Japan). The nutrient solution was based on a half-strength culture solution of the Otsuka House A-recipe (Otsuka Chemical Co. Ltd., Japan), as described previously (Sakamoto \& Suzuki, 2015). At 13 days after sowing (DAS), seedlings were transferred to a DFT hydroponic container $(34.5 \times 26.5 \times 8.2-\mathrm{cm}$ high) with continuous aeration under 250 $\mu \mathrm{mol} \mathrm{m} \mathrm{m}^{-2} \mathrm{PPF}$. A total of 12 seedlings were planted per container. The distance from the light source to the plant's bottom was $36 \mathrm{~cm}$. To avoid the diffusion of light out of the cultivation area, light-reflecting plates (MCPET; Furukawa Electric Co., Japan) were placed along all its margins. Nutrient solution was exchanged at every week. Shoot weight was obtained for all harvested shoot branches from a single plant. Leaf weight was obtained by adding the individual weights of all detached leaves from the harvested branches of a single plant. All plant weights were measured as fresh weight. In experiment 1 , characteristics of shoot branches were examined. In experiment 2, characteristics of shoot branches, leaves, and leaf indican content were examined. Three plants were subjected to each experimental plot in experiment 1 , and 12 plants in experiment 2 .

\subsection{Harvesting Methods}

Harvesting of shoot branches were initiated from 42 DAS in experiment 1, and from 29 DAS in experiment 2. To achieve continuous leaf production in this closed-cultivation system, two cutting methods of shoot branches were examined (Figure 1). The first method, named " $8 \mathrm{c}-\mathrm{M}$ " consisted of the harvesting of shoot branches at $>8 \mathrm{~cm}$ from the bottom level of the stem. To avoid removing young branches, we only harvested branches containing at least three fully expanded leaves. The second method, " $2 \mathrm{~b}-\mathrm{M}$ ", consisted of the harvesting of all branches at the bottom of the stem except for two young ones. Harvesting intervals were inconsistent in experiment 1 (7-36 days) and consistent in experiment 2 (7 days).

\subsection{Measurement of Indican}

The indican content was spectrophotometrically measured following modifications of the method reported elsewhere (Angelini et al., 2004; Gilbert et al., 2004). In brief, leaf disks (100 mg) from fully expanded secondary leaves were placed in $500 \mu \mathrm{L}$ of distilled water at $100^{\circ} \mathrm{C}$ for $10 \mathrm{~min}$. The sample was then cooled at room temperature. After the removal of leaf disks, $500 \mu \mathrm{L}$ of $1 \% \mathrm{HCl}$ (containing $10 \mathrm{mM} \mathrm{FeCl}_{3}$ ) were added to the solution and mixed thoroughly. After $30 \mathrm{~min}$, the blue indigo converted from the indican was spectrophotometrically measured at $600 \mathrm{~nm}$. A standard curve was prepared using an indican dilution series prepared by same steps.

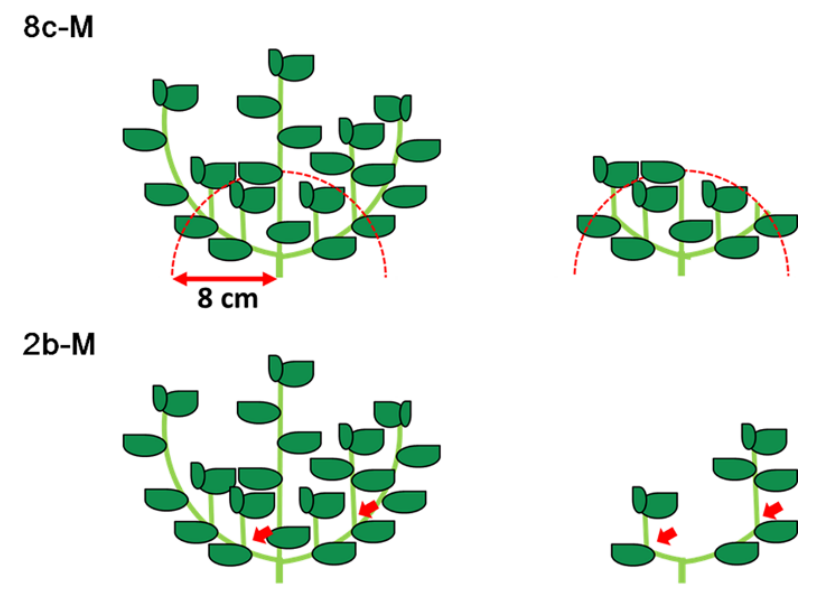

Figure 1. Schematic diagram of two harvesting methods for continuous harvesting of $P$. tinctorium. 8c-M; All shoot branches $>8 \mathrm{~cm}$ of the stem bottom are harvested except for branches containing less than 3 fully expanded leaves. 2b-M; All shoot branches are harvested at the bottom of stem except for two branches. Arrows show the two shoot branches remained to be harvested 


\section{Results and Discussion}

To achieve the maximum yield of indigo plant leaves by continuously harvesting the same plants, we designed two harvesting methods as described in Materials and Methods (Figure 1). Because P. tinctorium is a short-day plant which develops flower buds under prolonged dark periods, we generated a constant long-day environment in our closed-cultivation system to sustain constitutive leaf development without inducing flowering. In our cultivation system, flowering was not induced before 409 DAS (Figure 2). After harvesting branches, new ones emerged from the leaf proximal region, and sometimes from the stem-branching region.
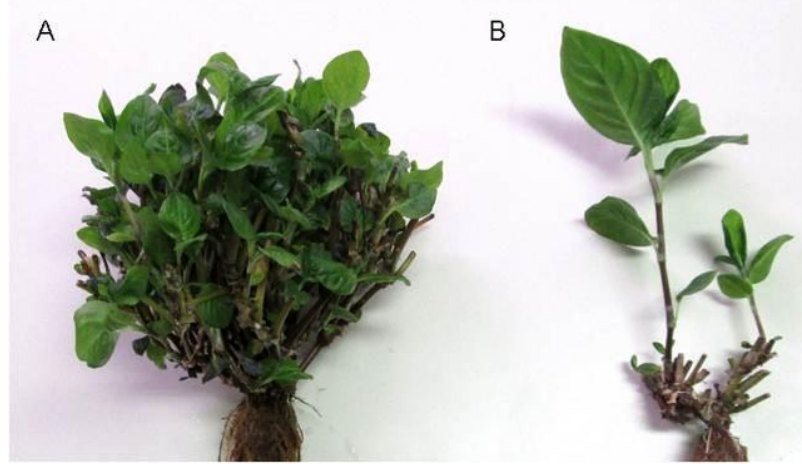

Figure 2. Morphological characteristics of $P$. tinctorium cultivar 'Kosenbon' harvested by two methods after 409 days after sowing in closed-cultivation system. A, plant harvested by $8 \mathrm{c}-\mathrm{M}$. B, plant harvested by $2 \mathrm{~b}-\mathrm{M}$
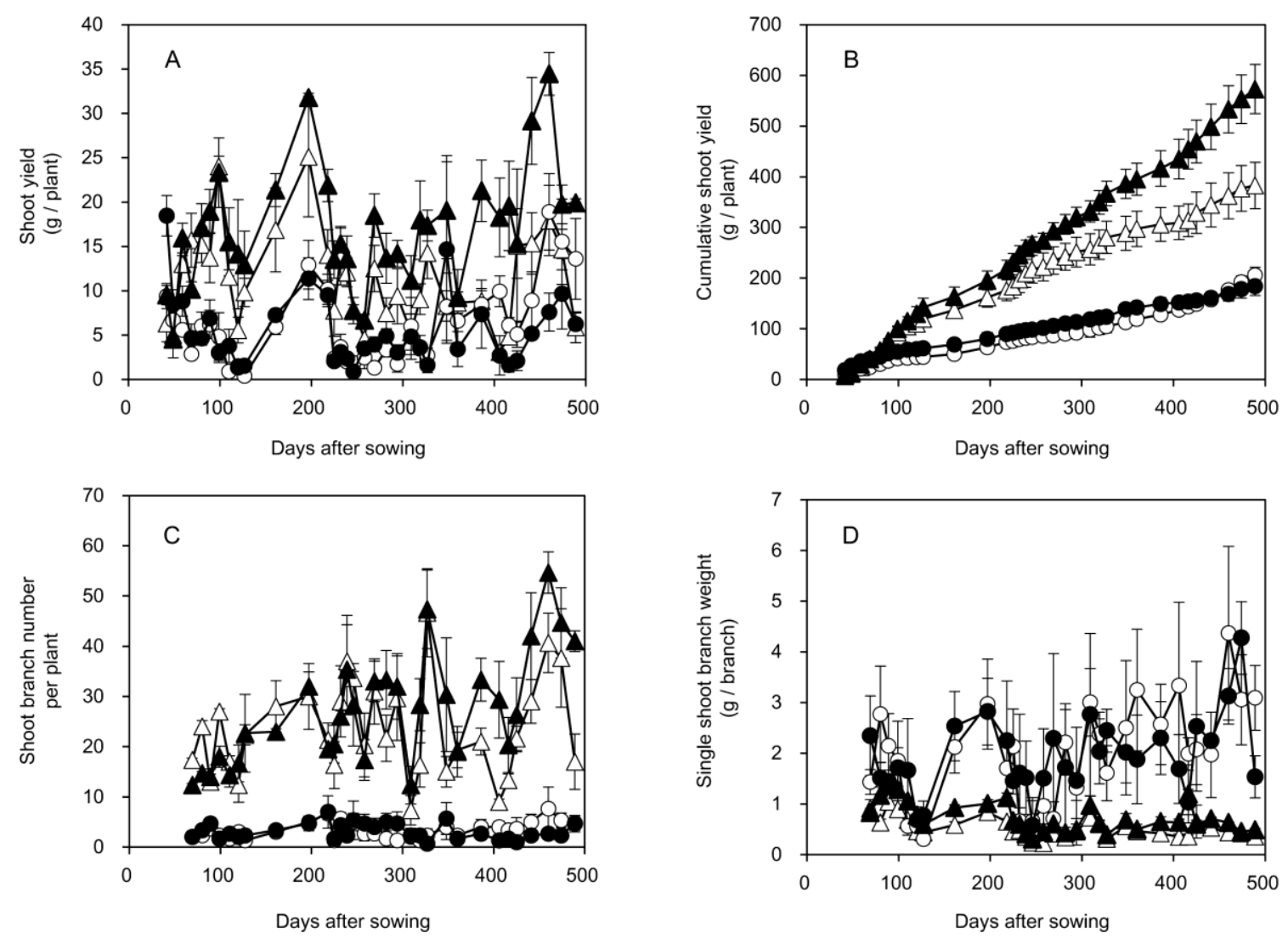

Figure 3. Effect of harvesting methods in P. tinctorium cultivars, 'Kosenbon' and 'Kojoko' on shoot yield (A), cumulative shoot yield (B), shoot branch number (C), and single shoot branch weight (D). Closed triangles, 'Kosenbon' harvested by 8c-M; open triangles, 'Kojoko' harvested by 8c-M; closed circles, 'Kosenbon' harvested by 2b-M; open circles, 'Kojoko' harvested by $2 \mathrm{~b}-\mathrm{M}$. Data are shown by the mean $\pm \mathrm{SE}(n=3)$ 
In experiment 1, both harvesting methods enabled sustainable yield of shoot branches for a total of 489 DAS (Figure 3). Harvested shoot weight was higher with the 8c-M than with the 2b-M (Figures 3A, 3B). The total shoot weight per 'Kosenbon' plants harvested with 8c-M during 489 DAS was $572.90 \mathrm{~g}$, that is highest within in this experiment. The total weight ratio of $8 \mathrm{c}-\mathrm{M} / 2 \mathrm{~b}-\mathrm{M}$ was 3.11 and 1.86 in 'Kosenbon' and 'Kojoko' respectively. Similarly, harvested branch number was higher in $8 \mathrm{c}-\mathrm{M}$ than in 2b-M (Figure 3C). Conversely, the weight of a single shoot branch was lower in plants harvested by 8c-M (Figure 3D). Plant morphologies at 409 DAS were different between plants harvested with the two methods (Figure 2). In plants harvested following 8c-M, the sizes of shoot branches and leaves were uniform compared with those from plants harvested by $2 \mathrm{~b}-\mathrm{M}$. After harvesting by $8 \mathrm{c}-\mathrm{M}$, many branches that could produce new shoot branches remained. In plants harvested by $2 \mathrm{~b}-\mathrm{M}$, the sizes of the shoot branches and leaves in each branch were variable and were in general larger than those from plants harvested following 8c-M (Figure 3D). Given that the application of 2b-M decreased total stem biomass compared to 8c-M (Figure 2), newly emerging and growing shoot meristems might have been suppressed in plants harvested by $2 \mathrm{~b}-\mathrm{M}$. To validate these results, we conducted experiment 2 with additional measurements using 'Kosenbon'.
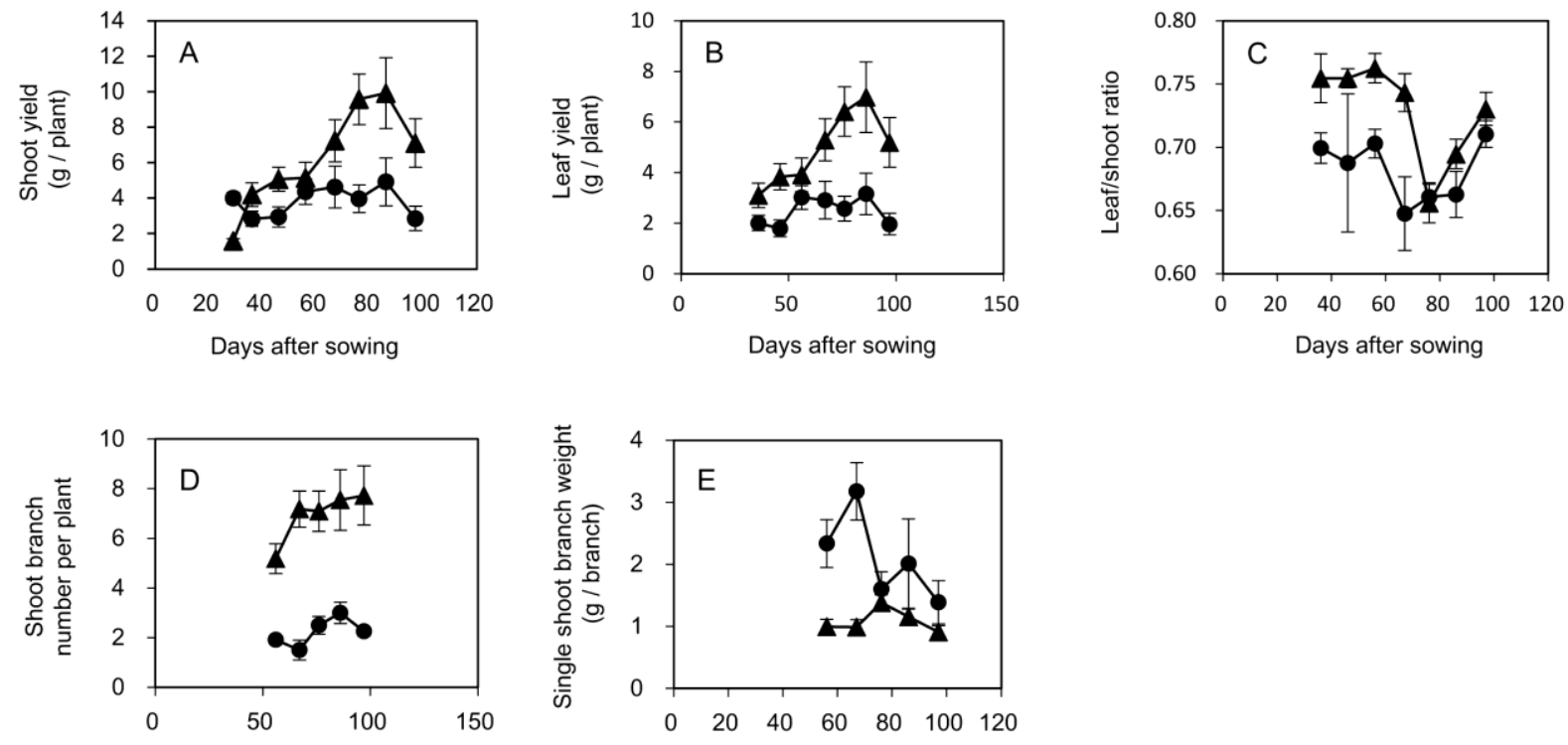

Days after sowing

Days after sowing

Figure 4. Effect of harvesting methods in P. tinctorium cultivar, 'Kosenbon' on shoot yield (A), leaf yield (B), leaf/shoot ratio (C), shoot branch number (D), and single shoot branch weight (E). Closed triangles, 'Kosenbon' harvested by $8 \mathrm{c}-\mathrm{M}$; closed circles, 'Kosenbon' harvested by $2 \mathrm{~b}-\mathrm{M}$. Data are shown by the mean \pm SE $(n=12)$

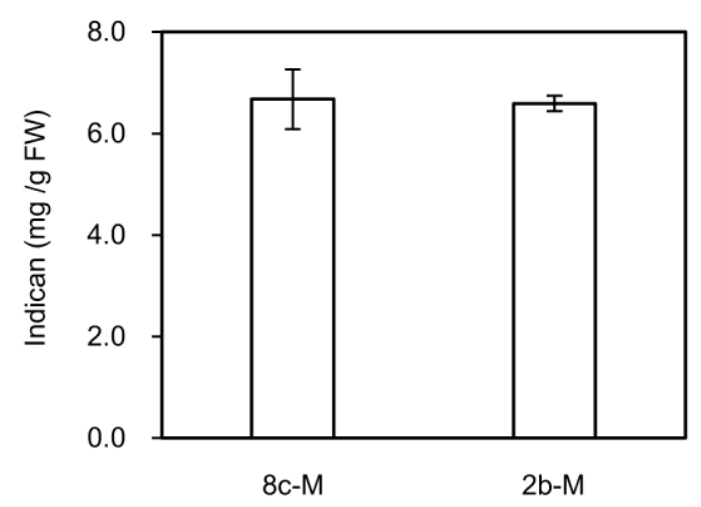

Figure 5. Effect of harvesting methods on the content of indican in leaves of $P$. tinctorium cultivar, 'Kosenbon'. Data are shown by the mean $\pm \operatorname{SE}(n=4)$ 
In experiment 2, the two harvesting methods showed similarities with experiment 1 in shoot weight, shoot branch number, and single shoot branch weight (Figures 4A, 4D, 4E). Leaf weight and shoot yield were increased in plants harvested with 8c-M (Figures 4A, 4B). The leaf/shoot ratio was higher in plants harvested by $8 \mathrm{c}-\mathrm{M}$ than in plants harvested by $2 \mathrm{~b}-\mathrm{M}$ (Figure $4 \mathrm{C}$ ).

Because $P$. tinctorium mainly contains indican in leaves and is rarely found in other structures (Minami et al., 2000), a higher ratio of leaf development may result in a higher indican production. To determine whether the applied harvesting methods influenced the production of indican, we measured indican contents of secondary fully expanded leaves from harvested shoot branches. As shown in Figure 5, no significant difference was observed between the two harvesting methods, suggesting that the harvesting method may not have an effect on the metabolic processes leading to indican synthesis. In previous studies, field grown $P$. tinctorium possessed $9.53 \mathrm{mg}$ (32.3 pmol) per g fresh weight of indican in leaves (Minami et al., 2000). In this study, leaf indican contents were 6.68 and $6.60 \mathrm{mg}$ per $\mathrm{g}$ fresh weight in $8 \mathrm{c}-\mathrm{M}$ and $2 \mathrm{~b}-\mathrm{M}$, respectively (Figure 5). Thus, there was not much difference in leaf indican levels between field and our hydroponically grown leaves, indicating that hydroponics can be alternative cultivation method to gain indican from P. tinctorium leaves.

Leaf position is important for the production of specific secondary metabolites in many leaf crops (McConkey et al., 2000; Minami et al., 2000; Koshiishi et al., 2001; Mohanpuria et al., 2009; Fischer et al., 2011). In tea, young leaves have activated caffeine synthetic pathways thereby containing substantially more caffeine than old leaves (Koshiishi et al., 2001; Mohanpuria et al., 2009). Likewise, along the main stem of sweet basil plants, younger leaves have more oil content than older leaves do (Fischer et al., 2011). Accordingly, younger immature leaves contain larger amounts of indican than older ones in P. tinctorium (Minami et al., 2000). To obtain indican from leaves in a high concentration, a larger proportion of young immature leaves is needed at harvest. Because the $8 \mathrm{c}-\mathrm{M}$ yield a higher number of shoot branches than the $2 \mathrm{~b}-\mathrm{M}$, the development of each branch might be suppressed. The application of the harvest method $8 \mathrm{c}-\mathrm{M}$ constitutes a reasonable approach to promote larger young immature leaf ratios therefore maximizing the yield of indican throughout the year in our P. tinctorium closed-cultivation system. By applying this method in closed-cultivation systems of other leaf crops that contain valuable components in young leaves, a sustainable production of such components may be also attained.

\section{References}

Angelini, L. G., Tozzi, S., \& Nassi o Di Nasso, N. (2004). Environmental factors affecting productivity, indican content, and indigo yield in Polygonum tinctorium Ait., a subtropical crop grown under temperate conditions. Journal of Agricultural and Food Chemistry, 52, 7541-7547. https://doi.org/10.1021/jf040312b

Bechtold, T., Turcanu, A., Geissler, S., \& Ganglberger, E. (2002). Process balance and product quality in the production of natural indigo from Polygonum tinctorium Ait. applying low-technology methods. Bioresource Technology, 81, 171-177. https://doi.org/10.1016/S0960-8524(01)00146-8

Campeol, E., Angelini, L. G., Tozzi, S., \& Bertolacci, M. (2006). Seasonal variation of indigo precursors in Isatis tinctoria L. and Polygonum tinctorium Ait. as affected by water deficit. Environmental Experimental Botany, 58, 223-233. https://doi.org/10.1016/j.envexpbot.2005.09.006

Chung, I., Kim, T., Bae, G., Lee, H., \& Chae, Y. (1996). Stimulation of indirubin production by KNO-3 depletion in indole-supplemented suspension culture of Polygonum tinctorium. Biotechnology Letters, 18, 947-950. https://doi.org/10.1007/BF00154627

Fischer, R., Nitzan, N., Chaimovitsh, D., Rubin, B., \& Dudai, N. (2011). Variation in essential oil composition within individual leaves of sweet basil (Ocimum basilicum L.) is more affected by leaf position than by leaf age. Journal of Agricultural and Food Chemistry, 59, 4913-4922. https://doi.org/10.1021/jf200017h

Gilbert, K. G., Maule, H. G., Rudolph, B., Lewis, M., Vandenburg, H., Sales, E., Tozzi, S., \& Cooke, D. T. (2004). Quantitative analysis of indigo and indigo precursors in leaves of Isatis spp. and Polygonum tinctorium. Biotechnology Progress, 20, 1289-1292. https://doi.org/10.1021/bp0300624

Hashimoto, T., Aga, H., Chaen, H., Fukuda, S., \& Kurimoto, M. (1999). Isolation and identification of anti-helicobacter pyrori compounds from Polygonum tinctorium Lour. Nature Medicine, 53, 27-31.

Iwaki, K., \& Kurimoto, M. (2002). Cancer preventive effects of the indigo plant, Polygonum tinctorium. Recent Research Developments in Cancer, 4, 429-437.

Kim, S. U., Song, K. S., Jung, D. S., Chae, Y. A., \& Lee, H. J. (1996). Production of indoxyl derivatives in indole-supplemented tissue cultures of Polygonum tinctorium. Planta Medica, 62, 54-56. 
https://doi.org/10.1055/s-2006-957797

Koo, J., \& Arain, S. (1998). Traditional Chinese medicine for the treatment of dermatologic disorders. Archives of Dermatology, 134, 1388-1393. https://doi.org/10.1001/archderm.134.11.1388

Koshiishi, C., Kato, A., Yama, S., Crozier, A., \& Ashihara, H. (2001). A new caffeine biosynthetic pathway in tea leaves: utilisation of adenosine released from the S - adenosyl - L - methionine cycle. FEBS Letters, 499, 50-54. https://doi.org/10.1016/S0014-5793(01)02512-1

Koya-Miyata, S., Kimoto, T., Micallef, M. J., Hino, K., Taniguchi, M., Ushio, S., Iwaki, K., Ikeda, M., \& Kurimoto, M. (2001). Prevention of azoxymethane-induced intestinal tumors by a crude ethyl acetate-extract and tryptanthrin extracted from Polygonum tinctorium Lour. Anticancer Research, 21, 3295-3300.

Kunikata, T., Takefuji, T., Aga, H., Iwaki, K., Ikeda, M., \& Kurimoto, M. (2000). Indirbin inhibits inflammatory reactions in delayed-type hypersensitivity. European Journal of Pharmacology, 410, 93-100. https://doi.org/10.1016/S0014-2999(00)00879-7

McConkey, M. E., Gershenzon, J., \& Croteau, R. B. (2000). Developmental regulation of monoterpene biosynthesis in the glandular trichomes of peppermint. Plant Physiology, 122, 215-224. https://doi.org/10.1104/pp.122.1.215

Micallef, M. J., Iwaki, K., Ishihara, T., Ushio, S., Aga, M., Kunikata, T., Koya-Miyata, S., Kimoto, T., Ikeda, M., Hino, K., \& Kurimoto, M. (2002). The natural plant product tryptanthrin ameliorates dextran sodium sulfate-induced colitis in mice. International Immunopharmacology, 2, 565-578. https://doi.org/10.1016/S1567-5769(01)00206-5

Minami, Y., Nishimura, O., Hara-Nishimura, I., Nishimura, M., \& Matsubara, H. (2000). Tissue and intracellular localization of indican and the purification and characterization of indican synthase from indigo plants. Plant and Cell Physiology, 41, 218-225. https://doi.org/10.1016/S1567-5769(01)00206-5

Mohanpuria, P., Kumar, V., Joshi, R., Gulati, A., Ahuja, P. S., \& Yadav, S. K. (2009). Caffeine biosynthesis and degradation in tea [Camellia sinensis (L.) O. Kuntze] is under developmental and seasonal regulation. Molecular Biotechnology, 43, 104-111. https://doi.org/10.1007/s12033-009-9188-2

Ricketts, R. (2006). Polygonum tinctorium: contemporary indigo farming and processing in Japan. Indirubin the red shade of indigo. Roscoff, Life in Progress Editions. 147-156.

Sakamoto, M., \& Suzuki, T. (2015). Elevated root-zone temperature modulates growth and quality of hydroponically grown carrots. Agricultural Sciences, 6, 749-757. https://doi.org/10.4236/as.2015.68072

Velho, S. R .K., Brum, L. F. W., Petter, C. O., dos Santos, J. H. Z., Simunicd, S., \& Kappa, W. H. (2017). Development of structured natural dyes for use into plastics. Dyes and Pigments, 136, 248-254. https://doi.org/10.1016/j.dyepig.2016.08.021

Young-Am, C., Yu, H. S., Song, J. S., Chun, H. K., \& Park, S. U. (2000). Indigo production in hairy root cultures of Polygonum tinctorium Lour. Biotechnology Letters, 22, 1527-1530. https://doi.org/10.1023/A:1005668625822

Xiao, Z., Hao, Y., Liu, B., \& Qian, L. (2002). Indirubin and meisoindigo in the treatment of chronic myelogenous leukemia in China. Leukemia \& Lymphoma, 43, 1763-1768. https://doi.org/10.1080/1042819021000006295

\section{Copyrights}

Copyright for this article is retained by the author(s), with first publication rights granted to the journal.

This is an open-access article distributed under the terms and conditions of the Creative Commons Attribution license (http://creativecommons.org/licenses/by/3.0/). 